\title{
Social vulnerability of rural households to flood hazards in western mountainous regions of Henan province, China
}

\author{
Delin $\mathrm{Liu}^{1}$ and ${\mathrm{Yue} \mathrm{Li}^{2}}^{2}$ \\ ${ }^{1}$ Safety and Emergency Management Research Center, Henan Polytechnic University, Jiaozuo 454000, China \\ ${ }^{2}$ Department of Civil Engineering, Case Western Reserve University, Cleveland, Ohio 44106, USA \\ Correspondence to: Delin Liu (liudelina@163.com), Yue Li (yueli@mtu.edu)
}

Received: 22 October 2015 - Published in Nat. Hazards Earth Syst. Sci. Discuss.: 4 November 2015

Revised: 20 March 2016 - Accepted: 2 May 2016 - Published: 13 May 2016

\begin{abstract}
Evaluating social vulnerability is a crucial issue in risk and disaster management. In this study, a household social vulnerability index (HSVI) to flood hazards was developed and used to assess the social vulnerability of rural households in western mountainous regions of Henan province, China. Eight key indicators were identified using existing literature and discussions with experts from multiple disciplines and local farmers, and their weights were determined using principle component analysis (PCA) and an expert scoring method. The results showed that (1) the ratio of perennial work in other places, hazard-related training and illiteracy ratio $(15+)$ were the most dominant factors of social vulnerability. (2) The numbers of high, moderate and low vulnerability households were 14, 64 and 16, respectively, which accounted for 14.9, 68.1 and $17.0 \%$ of the total interviewed rural households, respectively. (3) The correlation coefficient between household social vulnerability scores and casualties in a storm flood in July 2010 was significant at 0.05 significance level $(r=0.748)$, which indicated that the selected indicators and their weights were valid. (4) Some mitigation strategies to reduce household social vulnerability to flood hazards were proposed, which included (1) improving the local residents' income and their disaster-related knowledge and evacuation skills, (2) developing emergency plans and carrying out emergency drills and training, (3) enhancing the accuracy of disaster monitoring and warning systems and (4) establishing a specific emergency management department and comprehensive rescue systems. These results can provide useful information for rural households and local governments to prepare, mitigate and respond to flood hazards, and the corresponding strategies can help local house-
\end{abstract}

holds to reduce their social vulnerability and improve their ability to resist flood hazard.

\section{Introduction}

Flood hazard risk has increased over the past several decades and will continue to increase in the future, and the casualties and economic losses caused by flood disasters are following a similar and increasing trend in the world (Terry and Lisa, 2014; Walter, 2004). A number of studies have indicated that regional flood disasters are caused by the interaction of flood hazards and the vulnerability of flood-hazard-prone areas (Zhang et al., 2010; Hsieh, 2014). It is more difficult to prevent a flood hazard from becoming a flood disaster than to reduce the vulnerability of flood-hazard-prone areas (Liu and Liang, 2014). In order to effectively reduce the adverse effects of a flood disaster, it is necessary to enhance the understanding of the social vulnerability of flood-hazard-prone areas (Cutter et al., 2003, 2013; Zhang and You, 2014). Since Cutter developed a social vulnerability index to measure the social vulnerability to environmental hazards (Cutter et al., 2003), there has been growing concern and interest in this area (Bjarnadottir et al., 2011; Noriega and Ludwig, 2012; Zebardast, 2013; Siagian et al., 2014; Garbutt et al., 2015). For example, Noriega and Ludwig (2012) assessed the social vulnerability to local earthquake risk in Los Angeles County, California, United States, and they found that "knowledge of the relationship between earthquake hazard and the demographic characteristics of people in the area at risk is essential to mitigate the local impact from earthquakes". Zebardast (2013) constructed a social vulnerability index for 
earthquake hazards using a hybrid factor analysis and analytical network process model, and their case study showed that their method was a robust approach to construct a composite social vulnerability index. Using the social vulnerability index approach, Siagian et al. (2014) determined three main driving factors (socioeconomic status and infrastructure; gender, age and population growth; family structure) affecting social vulnerability to natural hazards in Indonesia. They also pointed out that the spatial distribution characteristics of social vulnerability to natural hazards could be easily identified when they were mapped using the ArcView geographical information system (GIS). Garbutt et al. (2015) presented an open source vulnerability index and mapped the social vulnerability to flood hazards in Norfolk, England. They found that flood affected areas were more likely to be composed of the elderly, sick and poor, and high vulnerability areas were found to be disproportionately impacted by flooding. All these studies provide a good understanding of social vulnerability to natural hazards. However, these studies focused on contributing to theoretical research or empirical study at national or regional scales (Garbutt et al., 2015; Zhou et al., 2014; Cutter and Finch, 2008; Cutter et al., 2013). Studies at the household level are very limited. Hence, studying and developing a household-level social vulnerability index for flood hazards is an important contribution to examine social vulnerability to natural hazards, because it can provide a new perspective from the individual house level in comparison to national or regional levels. Social vulnerability research at national or regional scales is macroscopical, where the results provide some macroscopical rather than specific and detailed information. For decision-making purposes, while studying at national or regional levels is useful for the government to make macrodecisions, it makes it difficult for the government or household to create operational coping strategies. For example, examining social vulnerability at household level provides details about why households' social vulnerability is at a high, low or moderate level. The households can then apply corresponding strategies to reduce their social vulnerability and improve their resilience to natural hazards accordingly. Meanwhile, the results can also be used by the government to be more specific in their decision-making. Rural areas are some of the most important flood-hazard-prone areas (Eakin and Bojorquez-Tapia, 2008; Ghimire et al., 2010), and more than 600 million people live in a rural area in China. Therefore, understanding social vulnerability at the rural household level is crucial for both rural households and local governments to prepare, mitigate and respond to natural hazards (Ghimire et al., 2010; Linnekamp et al., 2011).

The objectives of this paper were (1) to identify and prioritize key influencing factors of social vulnerability to flood hazards at household level, (2) to develop and use a household social vulnerability index to assess household social vulnerability to flood hazards in western mountainous regions of Henan province, China, and (3) to propose some targeted mitigation strategies to reduce household social vulnerability to flood hazards. The results could provide useful information for both rural households and local governments to prepare, mitigate and respond to flood disasters.

\section{Household social vulnerability index (HSVI)}

Several methods can be used to evaluate the social vulnerability to natural hazards, such as an assessment method based on historical disaster data and scenario-based, GIS-based and index-based assessment methods ( $\mathrm{Li}$ et al., 2008). Each assessment method has its advantages and disadvantages. In the assessment method based on historical disaster data, the established disaster database is used to construct a certain index and assess the disaster risk. For example, the disaster risk index can be obtained based on the EM-DAT database, which can show the population loss risk in a catastrophe by using the ratio of the number of deaths and the number of people exposed to a disaster. The advantages of this method are convenient data, simple calculation and accurate results, and the disadvantage is that it is just suitable for the macroscopic spatial scale, such as the global or national scale, and it is difficult to be used on a small spatial scale, such as the community or household scale. The scenario-based method is mainly based on the construction of different disaster scenarios, and then with the help of some models and numerical simulation software, can show the disaster evolution process and the vulnerability of hazard-prone areas. The advantage of this method is that it can be more convenient to display the processes and results, and its disadvantage is that the calculation processes are complex and need computer programming and profound mathematical knowledge. The steps of using a GIS-based method are (1) obtaining the data, (2) putting the data into GIS software, (3) running the overlay and spatial analysis function of GIS software and (4) calculating and mapping the results. The advantage of this method is that the results can be showed clearly in the form of maps, and its disadvantage is that all the data must be spatial data or be able to be changed to spatial data. The index-based assessment method was used here mainly because (1) it can effectively reveal the spatial and temporal patterns, as well as the evolution of vulnerability to a natural hazard at different scales, and (2) the assessment results among different regions are comparable due to the use of the same assessment index system (Cutter et al., 2003; Garbutt et al., 2015). There are five steps for using the index-based method to assess household social vulnerability to flood hazards as follows.

1. Determination of assessment scales: first of all, it is necessary to determine the research scale because the index-based assessment method can be used at different scales with different indictors. In this study, the rural household level was chosen. 
2. Selection of indictors: there are a number of factors affecting the social vulnerability of rural households to flood hazards. In order to make the selected factors as comprehensive as possible, two methods were used in this study. One method was to have discussions with experts from multiple disciplines and local farmers (Ghimire et al., 2010), and another was to obtain indicators from the existing literature (Cutter et al., 2003; Werg et al., 2013; Linnekamp et al., 2011).

3. Collection and processing of data: two methods, participatory rural appraisal (PRA) and household surveys, were used to gather the data. The PRA method was used to gather some supporting information (Chambers, 1994; Cornwall and Pratt, 2011), such as peoples' socioeconomic status and attitudes to flood hazards. A household survey (individual interviews) was used to collect the quantitative data of social vulnerability indicators (Ghimire et al., 2010).

When the data were gathered together, it was necessary to normalize them to establish a uniform dimension. Meanwhile, some indicators have favorable impacts, while some have unfavorable impacts on social vulnerability to flood hazards. In order to resolve these problems, extreme standardization was carried out.

Positive correlation indicators:

$x_{i}^{\prime}=\left(x_{i}-\min x_{i}\right) /\left(\max x_{i}-\min x_{i}\right)$.

Negative correlation indicators:

$x_{i}^{\prime}=\left(\max x_{i}-x_{i}\right) /\left(\max x_{i}-\min x_{i}\right)$,

where $x_{i}$ and $x_{i}^{\prime}$ are the original and standard values of indicator $i$, respectively, and $\max x_{i}$ and $\min x_{i}$ are the greatest and smallest values of the selected indicators' values, respectively.

4. Determination of index weights: the principle component analysis (PCA) method and the expert scoring method were used to determine the weights of each indicator. After the weights were obtained from the PCA, 20 experts from different fields (geography, hydrology, sociology and risk management) were invited to evaluate and adjust the results in order to make the weights more suitable for the local situation. The principles, steps and advantages of using PCA to determine index weight are described in detail in Qu (2012). The procedures used in this study are shown in Appendix B.

5. Calculation of household social vulnerability: based on the standardized data and determined index weight, a household social vulnerability index (HSVI) was constructed and used to study household social vulnerability to flood hazards. The HSVI can be expressed by

$\mathrm{HSVI}=\sum_{i=1}^{n} x_{i} \times w_{i}$

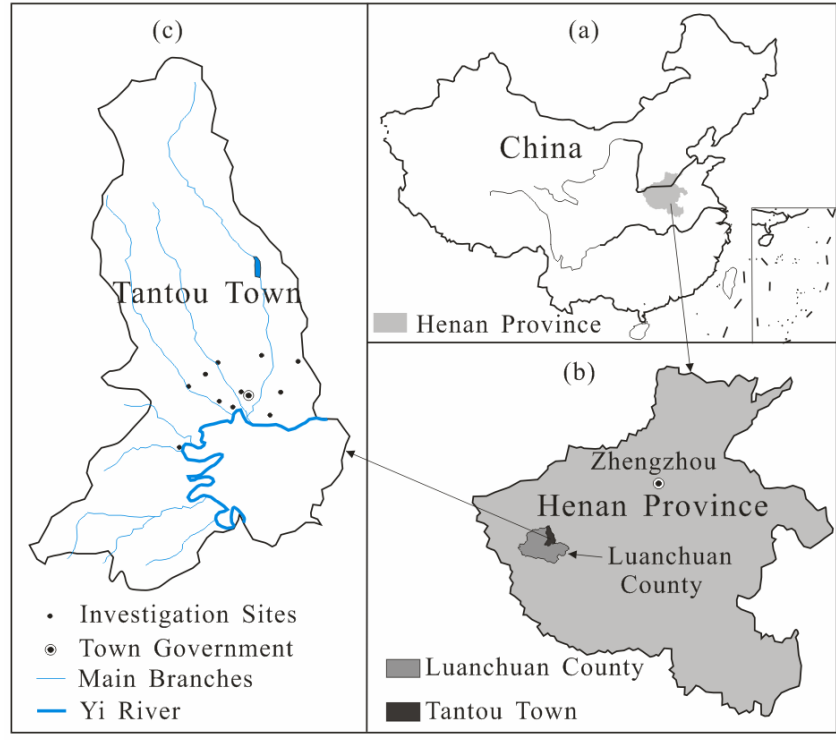

Figure 1. Maps of study area. (a) Location of Henan province in China. (b) Location of the study area in Henan province. (c) Investigation sites and distribution of rivers in the study area.

where HSVI is the household social vulnerability index and $x_{i}$ and $w_{i}$ are the standardized data and the weight value of index $i$, respectively.

\section{A case study}

\subsection{Study area}

Eleven villages located in the western mountainous regions of Henan province (the center regions of China) were chosen as the study area (Fig. 1). The total area of the 11 villages is $88.2 \mathrm{~km}^{2}$, most of which is hilly land. The area of arable land $\left(7.2 \mathrm{~km}^{2}\right)$ only accounts for $8.2 \%$ of the total area. The income per capita is less than USD 250 per year, and the poverty rate is higher than that in China $(\mathrm{Xi}, 2012)$. The annual mean precipitation is about $750 \mathrm{~mm}$, about $60 \%$ of which occurs during the period of June to September. Rainstorms can easily result in a flood because of the steep and narrow riverbeds, poor flood discharge capacity and intense human activities (Shao et al., 2013).

These villages were chosen as the study area mainly because (1) the conditions of nature, society and economy are very similar to those of most other villages in the western mountainous regions of Henan province, and (2) it was easy to obtain sufficient and reliable data because these villages had undergone some severe flood disasters in recent years.

\subsection{Selected indictors and weights}

Based on the existing literature (Cutter et al., 2003; Werg et al., 2013; Linnekamp et al., 2011) and interactive discus- 
sions with 30 local farmers and 20 experts from different study fields (geography, hydrology, sociology and risk management), and using the semi-structured interview method (Harrell and Bradley, 2009), eight indicators were identified to assess the social vulnerability at household level to flood hazards. The selected indicators and their weights, definitions, measurement methods and underlying assumptions are shown in Table 1. The weight of each indicator was determined using the PCA method (Qu, 2012) and the expert scoring method. Table 1 showed that the indicator with the biggest weight value (0.17) was the ratio of perennial work in other places, the indicator with the smallest weight value (0.09) was the dependency ratio and the weight values of other indicators ranged from 0.10 to 0.14 .

\subsection{Data collection}

A door-to-door questionnaire investigation was carried out by the author's research team during the period of 10-15 April 2014. The requirement for participants was that they could answer a questionnaire and have been affected by a flood disaster. One hundred households were chosen according to the local officials' suggestions. The criteria to choose survey targets were that (1) the household had been affected by flood hazard, (2) the flood hazards had resulted in property damage or loss of life, (3) the family characteristics should be as different as possible and (4) the residents in the households were able to understand and answer a questionnaire clearly. All the 100 copies of the questionnaire were collected on the spot, and 6 copies were eliminated due to the inconsistent and incomplete answers. The standard data of the questionnaire are shown in Appendix A.

\subsection{Household social vulnerability assessment}

According to the factors shown in Table 1, the data collected from 94 households were firstly processed by using Eqs. (1) and (2). Secondly, the household social vulnerability (HSV) scores were calculated using Eq. (1). Lastly, the HSV scores were divided into three grades using the mean value (MV) and standard deviation (SD) of HSV scores. If the HSV score was greater than 1 SD from the MV [(HSV score $)>(\mathrm{MV}+1 \mathrm{SD})]$, the household was in the high vulnerability category, if the HSV score was lower than $1 \mathrm{SD}$ from the MV [(HSV score) <(MV - 1 SD)], the household was in the low vulnerability category and other HSV scores $[(\mathrm{MV}-1 \mathrm{SD}) \leq(\mathrm{HSV}$ score $) \leq(\mathrm{MV}+1 \mathrm{SD})]$ were in the moderate vulnerability category. In this study, the SD, MV, maximum and minimum of HSV scores were $0.11,0.59,0.21$ and 0.87 , respectively. Therefore, the ranges of low, moderate and high vulnerability category for a household were [0.21, $0.48),[0.48,0.70]$, and $(0.70,0.87]$, respectively.

The results showed that (1) the numbers of high, moderate and low vulnerability households were 14, 64 and 16, respectively, which accounted for $14.9 \%, 68.1 \%$ and $17.0 \%$ of the total interviewed households, respectively. (2) Seen from the spatial distribution of household social vulnerability in the 11 villages (Fig. 2), there were three high vulnerable villages, Manying, Shimen and Zhaozhuang. (3) Table 2 reveals that compared with the low vulnerability households, the ratio of perennial work in other places, hazard-related training and illiteracy ratio $(15+)$ had the greatest impacts on moderate and high vulnerable households, and the ratios of high and moderate vulnerability scores to low vulnerability scores were greater than 2.5 and 3.3, respectively. Access to hazard-related information and income per capita had the smallest impact, while the impacts of family size and vehicles per capita were moderate (Table 2). (4) The correlation coefficient of HSV scores and casualties was valid at 0.05 significance level $(r=0.748)$.

\section{Discussion}

\subsection{Key problems in using index-based assessment method}

The index-based assessment method is one of the most widely used assessment methods (Cutter et al., 2003; Garbutt et al., 2015; Cutter and Finch, 2008); however three problems, index system, index weight and index validity, should be considered before using this method. (1) There are a number of factors affecting the social vulnerability of households. On the one hand, it is difficult to describe the characteristics of social vulnerability if there were only few indicators, but on the other hand, if too many indicators were selected and used, there were also some problems, such as inaccessible data, complex calculation and poor operability (Cutter et al., 2003; Murphy and Scott, 2014). It is important that the selected indicators are in a manageable level, for which the PCA is a good method to use (Liu et al., 2013). For example, Cutter and Finch (2008) used the PCA method to reduce 42 social vulnerability variables to 11 independent indicators, and studied the temporal and spatial changes in social vulnerability to natural hazards using the indicators. In this paper, eight indicators were selected based on existing references and discussions with experts from multiple disciplines and local farmers (Table 1). Eight indicators should be a manageable level and they are easily quantified (Cutter and Finch, 2008). (2) Index weights are crucial to the accuracy of assessment results. The methods used to determine index weight can be divided into three categories. The first category includes subjective weighting methods, such as Delphi and experts grading method. The second category includes objective weighting methods, such as the entropy method and PCA. The third category includes integrated subjective and objective weighting methods, such as the analytic hierarchy process. Each of these methods has its advantages and disadvantages (Wang et al., 2012), and different index weights could affect the scores of assessment results. Therefore, how 
Table 1. Selected indicators and their weights, definitions, measurement and underlying assumptions to social vulnerability (SV).

\begin{tabular}{|c|c|c|c|c|}
\hline Indicator & Weight & Definition & Measurement & Assumptions \\
\hline Family size & 0.13 & $\begin{array}{l}\text { Total number of family mem- } \\
\text { bers }\end{array}$ & Number of family members & $\begin{array}{l}\text { The more the family mem- } \\
\text { bers, the higher the SV be- } \\
\text { cause there are more people } \\
\text { exposed to flood hazards in a } \\
\text { big family. }\end{array}$ \\
\hline Dependency ratio & 0.09 & $\begin{array}{l}\text { Number of dependents (aged } \\
0-18 \text { and over the age of } \\
65 \text { ) compared to number of } \\
\text { working-age people (aged 19- } \\
64)\end{array}$ & $\begin{array}{l}\text { Number of } \\
\text { dependents/number of people } \\
\text { aged from } 19 \text { to } \\
64) \times 100 \%\end{array}$ & $\begin{array}{l}\text { The larger the ratio, the greater } \\
\text { the burden on the average } \\
\text { working-age people, and the } \\
\text { higher the SV. }\end{array}$ \\
\hline $\begin{array}{l}\text { Illiteracy ratio } \\
(15+)\end{array}$ & 0.12 & $\begin{array}{l}\text { Rate of illiteracy (people are } \\
\text { over the age of } 15 \text { and with in- } \\
\text { ability to read and write) com- } \\
\text { pared to family size }\end{array}$ & $\begin{array}{l}\text { (Number of illiteracy/family } \\
\text { size }) \times 100 \%\end{array}$ & $\begin{array}{l}\text { The higher the ratio, the lower } \\
\text { the ability to access hazard- } \\
\text { related information and re- } \\
\text { sources, and the higher the SV. }\end{array}$ \\
\hline $\begin{array}{l}\text { The ratio of } \\
\text { perennial } \\
\text { work } \\
\text { in other places }\end{array}$ & 0.17 & $\begin{array}{l}\text { Number of people (who work } \\
\text { in other places and cannot re- } \\
\text { turn home for a long time) } \\
\text { compared to family size }\end{array}$ & $\begin{array}{l}\text { Number of people who work } \\
\text { in other place/family size }\end{array}$ & $\begin{array}{l}\text { The more people work in other } \\
\text { place, the higher dependents } \\
\text { ratio, and the higher the SV. }\end{array}$ \\
\hline Income per capita & 0.14 & $\begin{array}{l}\text { The average income earned } \\
\text { per person in a family }\end{array}$ & $\begin{array}{l}\text { The total family } \\
\text { income/family size }\end{array}$ & $\begin{array}{l}\text { The higher the income per } \\
\text { capita, the more the accumula- } \\
\text { tion of wealth and the greater } \\
\text { the ability to access hazard- } \\
\text { related information and re- } \\
\text { sources, and the lower the SV. }\end{array}$ \\
\hline $\begin{array}{l}\text { Access to hazard- } \\
\text { related } \\
\text { information }\end{array}$ & 0.12 & $\begin{array}{l}\text { The ability to receive disaster } \\
\text { risk information }\end{array}$ & $\begin{array}{l}\text { Number of information- } \\
\text { receiving tools, including } \\
\text { telephone, cell phone, TV } \\
\text { and Internet }\end{array}$ & $\begin{array}{l}\text { The more information- } \\
\text { receiving tools, the greater } \\
\text { the ability to access risk } \\
\text { information, and the lower the } \\
\text { SV. }\end{array}$ \\
\hline Vehicles per capita & 0.10 & $\begin{array}{l}\text { Total number of vehicles in } \\
\text { a family compared to family } \\
\text { size }\end{array}$ & $\begin{array}{l}\text { Number of vehicles/family } \\
\text { size }\end{array}$ & $\begin{array}{l}\text { The more vehicles per capita, } \\
\text { the greater the ability to evac- } \\
\text { uate from a disaster, and the } \\
\text { lower the SV. }\end{array}$ \\
\hline $\begin{array}{l}\text { Hazard-related } \\
\text { training }\end{array}$ & 0.14 & $\begin{array}{l}\text { Times hazard-related training } \\
\text { has been taken part in in the } \\
\text { last } 5 \text { years }\end{array}$ & $\begin{array}{l}\text { No }=0 ; \text { one time }=0.5 \\
\text { two or more times }=1\end{array}$ & $\begin{array}{l}\text { The knowledge, attitudes and } \\
\text { response to disasters can be } \\
\text { improved by attending train- } \\
\text { ing (listening to lectures and } \\
\text { participating in emergency ex- } \\
\text { ercises). Therefore, the more } \\
\text { times such training is attended, } \\
\text { the lower the SV. }\end{array}$ \\
\hline
\end{tabular}

Note: the indicators of the ratio of perennial work in other places and access to hazard-related information came from experts and existing references (Cutter et al., 2003; Werg et al., 2013; Linnekamp et al., 2011).

to determine the reasonable index weights is an important problem to be solved in assessment research. (3) A comparison between the assessment results and a post-event situation is a feasible method to test the validity of selected indicators and their weights. In this study, we calculated the correlation coefficient between scores of household social vulnerability and the casualties of each household in a storm flood in July 2010. The results showed that the correlation coefficient was significant at 0.05 significance level $(r=0.748)$, which in- dicated that the selected social vulnerability indicators and their weights were valid.

\subsection{How to reduce social vulnerability}

There has been much exciting research on how to reduce social vulnerability, but this has mainly focused on country, region and river basin scales. For example, based on the analysis of driving factors of social vulnerability to natural hazards in Indonesia, Siagian et al. thought that it was a good 


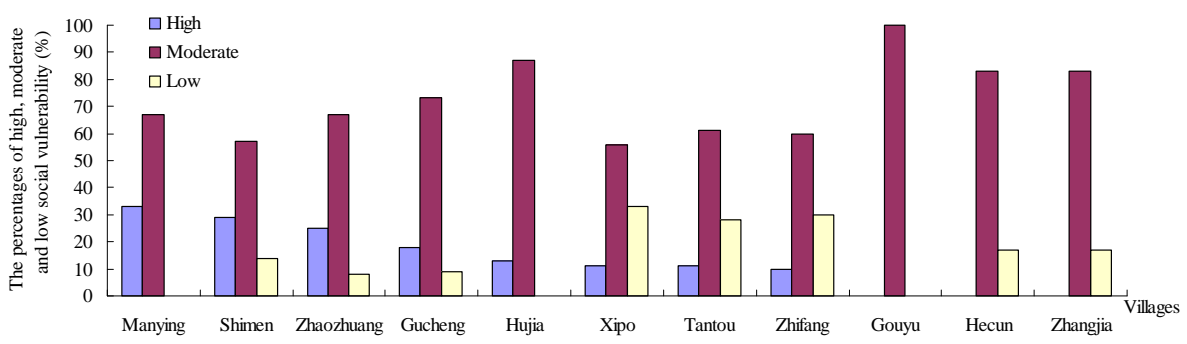

Figure 2. Spatial distribution of household social vulnerability (\%).

Table 2. The mean scores of low, moderate and high vulnerable households for each index $(\times 100)$.

\begin{tabular}{llllll}
\hline Indicator & Low & Moderate & High & Ms / Ls & Hs / Ls \\
\hline Ratio of perennial work in other places & 2.03 & 7.19 & 11.4 & 3.54 & 5.62 \\
Hazard-related training & 2.19 & 6.45 & 9.5 & 2.95 & 4.34 \\
Illiteracy ratio (15+) & 2.00 & 5.14 & 6.66 & 2.58 & 3.34 \\
Family size & 6.26 & 8.31 & 11.03 & 1.33 & 1.76 \\
Vehicles per capita & 5.68 & 7.62 & 8.61 & 1.34 & 1.52 \\
Dependency ratio & 1.97 & 2.14 & 2.78 & 1.08 & 1.41 \\
Access to hazard-related information & 9.83 & 11.02 & 11.64 & 1.12 & 1.18 \\
Income per capita & 11.23 & 12.48 & 12.99 & 1.11 & 1.16 \\
\hline
\end{tabular}

Note: Ms / Ls is the ratio of moderate vulnerability score to low vulnerability score;

$\mathrm{Hs} / \mathrm{Ls}$ is the ratio of high vulnerability score to low vulnerability score.

way to reduce the social vulnerability by integrating social vulnerability maps in early warning systems (Siagian et al., 2014). Chen et al. (2013) put forward some suggestions to reduce social vulnerability in the Yangtze River Delta region, such as reducing the unequal distribution of social resources and improving the employment rate (Chen et al., 2013). The studies at household level were limited, especially regarding flood hazards (Chen et al., 2013; Siagian et al., 2014). In this study, the target strategies to reduce the household social vulnerability to flood disasters were discussed based on the assessment results (Table 2). At first, the ratio of perennial work in other places should be reduced as soon as possible, because it was the most dominant factor which resulted in high vulnerability. According to the investigation, in the 94 households, the number of people whose work in other places is perennial due to limited local job opportunities was 141 , which accounted for $27.2 \%$ of the total people (519), $52.4 \%$ of the population aged between 18 and 64 and $82.5 \%$ of the people aged between 18 and 49, respectively. In order to solve this problem, the reasons why the local residents preferred working in other places to staying at home need to be understood. The most important reason was that the high cost of farming and low price of agricultural products resulted in the low income of a family. Besides, the agricultural income in these regions is not guaranteed due to the variation of climate conditions. Another important reason was that there were few companies or factories to provide work opportunities for local residents. Therefore, the ratio of perennial work in other places should be reduced by estab- lishing agricultural insurance and increasing work opportunities to guarantee the local residents' income. The disasterrelated knowledge and evacuation skills of the local residents should then be enhanced through disaster-related training. Some unexpected observations were found during this survey. For example, $64.2 \%$ of the people interviewed thought there were no occurrences of floods in this region, while there had been three occurrences of flood catastrophes in the past 50 years. Only $23.2 \%$ of the people interviewed regularly received training pertaining to hazard or evacuation. As a result, a certain level of training about flood hazards should be held often in order to improve the hazard-related knowledge and evacuation skills of local residents. Finally, the literacy ratio should be improved. From the perspectives of communities or governments, the following measures could be effective to reduce the social vulnerability to flood disasters: (1) preparing flood hazards mitigation plans based on risk assessment results of flood hazards, (2) improving the accuracy of disaster monitoring and warning systems, (3) establishing specialized emergency management department and comprehensive rescue systems and (4) developing an emergency plan and carrying out emergency drills and training.

\section{Conclusions}

In order to understand the rural household social vulnerability to flood hazards, a household social vulnerability index was developed, and the household social vulnerability of the 
selected 11 villages was assessed. Some mitigation strategies to reduce the household social vulnerability were proposed based on the assessment results. There are some interesting findings. (1) Eight key indicators, influencing social vulnerability to flood hazards at household level, were identified using existing literature and interactive discussions with experts and local farmers, and the weight of each indicator was determined using the PCA method and the expert scoring method. (2) The results showed that the numbers of high, moderate and low vulnerability households were 14, 64 and 16, respectively, which accounted for $14.9 \%$, $68.1 \%$ and $17.0 \%$ of the total evaluated households, respectively. The correlation coefficient of HSV scores and casualties was significant at 0.05 significance level $(r=0.748)$, which indicated that the selected social vulnerability indicators and their weights were valid. (3) The ratio of perennial work in other places, hazard-related training and illiteracy ratio $(15+)$ were the most dominant factors which resulted in higher vulnerability. Access to hazard-related information and income per capita had the smallest impact on higher vulnerability, and the impacts of family size and vehicles per capita were moderate. (4) To reduce the household social vulnerability to flood hazards, reducing the ratio of perennial work in other places, and enhancing the hazard-related knowledge and evacuation skills were effective measures and must be carried out as soon as possible. 


\section{Appendix A}

Table A1. The standard data and assessment results.

\begin{tabular}{|c|c|c|c|c|c|c|c|c|c|c|}
\hline & FS & DR & IR & RPW & PCI & AHI & VPC & HRT & Scores & Ranks \\
\hline 1 & 1.00 & 0.25 & 0.42 & 1.00 & 0.97 & 1.00 & 1.00 & 1.00 & 0.87 & high \\
\hline 2 & 1.00 & 0.25 & 0.42 & 1.00 & 1.00 & 1.00 & 1.00 & 0.50 & 0.80 & high \\
\hline 3 & 0.57 & 1.00 & 1.00 & 0.63 & 0.91 & 0.96 & 0.53 & 0.50 & 0.76 & high \\
\hline 4 & 1.00 & 0.25 & 0.42 & 0.79 & 0.97 & 1.00 & 0.87 & 0.50 & 0.75 & high \\
\hline 5 & 0.86 & 0.19 & 0.72 & 0.68 & 0.91 & 0.99 & 1.00 & 0.50 & 0.75 & high \\
\hline 6 & 0.43 & 0.25 & 0.83 & 0.79 & 0.80 & 0.94 & 0.67 & 1.00 & 0.74 & high \\
\hline 7 & 0.86 & 0.33 & 0.23 & 0.46 & 0.95 & 0.99 & 1.00 & 1.00 & 0.74 & high \\
\hline 8 & 0.86 & 0.33 & 0.48 & 0.68 & 0.95 & 0.99 & 1.00 & 0.50 & 0.74 & high \\
\hline 9 & 0.86 & 0.33 & 0.23 & 0.46 & 0.95 & 0.99 & 0.86 & 1.00 & 0.73 & high \\
\hline 10 & 0.86 & 0.19 & 0.72 & 0.68 & 0.88 & 0.91 & 0.86 & 0.50 & 0.72 & high \\
\hline 11 & 0.86 & 0.19 & 0.72 & 0.68 & 0.91 & 0.91 & 0.81 & 0.50 & 0.72 & high \\
\hline 12 & 0.86 & 0.19 & 0.72 & 0.68 & 0.91 & 0.91 & 0.81 & 0.50 & 0.72 & high \\
\hline 13 & 0.86 & 0.33 & 0.23 & 0.46 & 0.91 & 0.99 & 0.81 & 1.00 & 0.71 & high \\
\hline 14 & 1.00 & 0.25 & 0.63 & 0.40 & 0.97 & 1.00 & 0.83 & 0.50 & 0.70 & high \\
\hline 15 & 0.57 & 0.17 & 0.67 & 0.32 & 0.85 & 0.96 & 1.00 & 1.00 & 0.70 & moderate \\
\hline 16 & 0.43 & 0.25 & 0.83 & 0.79 & 0.93 & 0.94 & 0.67 & 0.50 & 0.69 & moderate \\
\hline 17 & 0.71 & 0.25 & 0.55 & 0.52 & 0.93 & 0.98 & 1.00 & 0.50 & 0.69 & moderate \\
\hline 18 & 0.71 & 0.25 & 0.55 & 0.52 & 0.93 & 0.98 & 1.00 & 0.50 & 0.69 & moderate \\
\hline 19 & 0.71 & 0.25 & 0.55 & 0.52 & 0.93 & 0.98 & 1.00 & 0.50 & 0.69 & moderate \\
\hline 20 & 1.00 & 0.25 & 0.42 & 1.00 & 0.90 & 0.94 & 0.75 & 0.00 & 0.69 & moderate \\
\hline 21 & 0.86 & 0.19 & 0.72 & 0.68 & 0.88 & 0.91 & 0.53 & 0.50 & 0.69 & moderate \\
\hline 22 & 0.71 & 0.25 & 0.55 & 0.52 & 0.89 & 0.89 & 0.45 & 1.00 & 0.69 & moderate \\
\hline 23 & 0.43 & 0.25 & 0.83 & 0.79 & 0.87 & 0.94 & 0.67 & 0.50 & 0.68 & moderate \\
\hline 24 & 0.71 & 0.50 & 0.28 & 0.27 & 0.89 & 0.98 & 0.78 & 1.00 & 0.68 & moderate \\
\hline 25 & 0.71 & 0.25 & 0.55 & 0.52 & 0.98 & 0.98 & 0.78 & 0.50 & 0.67 & moderate \\
\hline 26 & 0.57 & 0.17 & 0.67 & 0.32 & 0.85 & 0.96 & 0.73 & 1.00 & 0.67 & moderate \\
\hline 27 & 0.71 & 0.25 & 0.55 & 0.52 & 0.93 & 0.98 & 0.78 & 0.50 & 0.67 & moderate \\
\hline 28 & 0.86 & 0.19 & 0.72 & 0.68 & 0.95 & 0.99 & 0.81 & 0.00 & 0.66 & moderate \\
\hline 29 & 0.71 & 0.25 & 0.55 & 0.52 & 0.89 & 0.98 & 0.78 & 0.50 & 0.66 & moderate \\
\hline 30 & 0.71 & 0.25 & 0.55 & 0.52 & 0.98 & 0.98 & 0.61 & 0.50 & 0.66 & moderate \\
\hline 31 & 0.71 & 0.25 & 0.55 & 0.52 & 0.93 & 0.89 & 0.78 & 0.50 & 0.65 & moderate \\
\hline 32 & 0.71 & 0.25 & 0.55 & 0.52 & 0.89 & 0.89 & 0.78 & 0.50 & 0.65 & moderate \\
\hline 33 & 0.71 & 0.25 & 0.55 & 0.52 & 0.89 & 0.98 & 0.67 & 0.50 & 0.65 & moderate \\
\hline 34 & 0.71 & 0.25 & 0.55 & 0.27 & 0.93 & 0.98 & 1.00 & 0.50 & 0.64 & moderate \\
\hline 35 & 0.71 & 0.25 & 0.55 & 0.52 & 0.89 & 0.98 & 0.61 & 0.50 & 0.64 & moderate \\
\hline 36 & 0.71 & 0.25 & 0.55 & 0.52 & 0.89 & 0.80 & 0.78 & 0.50 & 0.64 & moderate \\
\hline 37 & 0.57 & 0.17 & 0.67 & 0.32 & 0.91 & 0.96 & 1.00 & 0.50 & 0.64 & moderate \\
\hline 38 & 0.86 & 0.33 & 0.23 & 0.46 & 0.95 & 0.99 & 0.67 & 0.50 & 0.64 & moderate \\
\hline 39 & 0.71 & 0.25 & 0.55 & 0.27 & 0.89 & 0.98 & 0.78 & 0.50 & 0.62 & moderate \\
\hline 40 & 0.57 & 0.17 & 0.67 & 0.32 & 0.91 & 0.96 & 0.80 & 0.50 & 0.62 & moderate \\
\hline 41 & 0.71 & 0.50 & 0.28 & 0.27 & 0.89 & 0.98 & 0.83 & 0.50 & 0.61 & moderate \\
\hline 42 & 0.71 & 0.25 & 0.55 & 0.27 & 0.89 & 0.89 & 0.83 & 0.50 & 0.61 & moderate \\
\hline 43 & 0.71 & 0.25 & 0.55 & 0.27 & 0.89 & 0.89 & 0.83 & 0.50 & 0.61 & moderate \\
\hline 44 & 0.57 & 0.17 & 0.67 & 0.32 & 0.91 & 0.96 & 0.73 & 0.50 & 0.61 & moderate \\
\hline 45 & 0.57 & 0.17 & 0.67 & 0.32 & 0.85 & 0.96 & 0.80 & 0.50 & 0.61 & moderate \\
\hline 46 & 0.71 & 0.25 & 0.55 & 0.27 & 0.89 & 0.89 & 0.78 & 0.50 & 0.61 & moderate \\
\hline 47 & 0.57 & 0.17 & 0.67 & 0.32 & 0.91 & 0.86 & 0.80 & 0.50 & 0.60 & moderate \\
\hline 48 & 0.43 & 0.25 & 0.83 & 0.79 & 0.80 & 0.94 & 0.67 & 0.00 & 0.60 & moderate \\
\hline 49 & 0.57 & 0.17 & 0.33 & 0.32 & 0.96 & 0.96 & 1.00 & 0.50 & 0.60 & moderate \\
\hline 50 & 0.43 & 0.25 & 0.42 & 0.40 & 0.87 & 0.94 & 1.00 & 0.50 & 0.60 & moderate \\
\hline
\end{tabular}


Table A1. Continued.

\begin{tabular}{|c|c|c|c|c|c|c|c|c|c|c|}
\hline 51 & 0.71 & 0.25 & 0.55 & 0.27 & 0.89 & 0.98 & 0.61 & 0.50 & 0.60 & moderate \\
\hline 52 & 0.71 & 0.50 & 0.28 & 0.27 & 0.89 & 0.89 & 0.78 & 0.50 & 0.60 & moderate \\
\hline 53 & 0.57 & 0.17 & 0.00 & 0.32 & 0.91 & 0.86 & 0.80 & 1.00 & 0.59 & moderate \\
\hline 54 & 0.57 & 0.17 & 0.67 & 0.32 & 0.85 & 0.86 & 0.73 & 0.50 & 0.59 & moderate \\
\hline 55 & 0.86 & 0.33 & 0.23 & 0.46 & 0.95 & 0.99 & 0.86 & 0.00 & 0.59 & moderate \\
\hline 56 & 0.86 & 0.33 & 0.23 & 0.46 & 0.91 & 0.84 & 0.38 & 0.50 & 0.58 & moderate \\
\hline 57 & 0.57 & 0.17 & 0.33 & 0.63 & 0.85 & 0.86 & 0.53 & 0.50 & 0.58 & moderate \\
\hline 58 & 0.71 & 0.50 & 0.28 & 0.27 & 0.89 & 0.89 & 0.61 & 0.50 & 0.58 & moderate \\
\hline 59 & 0.43 & 0.25 & 0.83 & 0.79 & 0.87 & 0.80 & 0.41 & 0.00 & 0.57 & moderate \\
\hline 60 & 0.57 & 0.17 & 0.33 & 0.32 & 0.85 & 0.96 & 0.80 & 0.50 & 0.57 & moderate \\
\hline 61 & 0.57 & 0.17 & 0.33 & 0.32 & 0.85 & 0.96 & 0.80 & 0.50 & 0.57 & moderate \\
\hline 63 & 0.43 & 0.25 & 0.00 & 0.79 & 0.87 & 0.80 & 0.67 & 0.50 & 0.57 & moderate \\
\hline 64 & 0.86 & 0.33 & 0.23 & 0.46 & 0.91 & 0.91 & 0.67 & 0.00 & 0.55 & moderate \\
\hline 65 & 0.57 & 0.17 & 0.00 & 0.32 & 0.91 & 0.86 & 1.00 & 0.50 & 0.54 & moderate \\
\hline 66 & 0.43 & 0.25 & 0.42 & 0.40 & 0.80 & 0.80 & 0.67 & 0.50 & 0.54 & moderate \\
\hline 67 & 0.71 & 0.25 & 0.55 & 0.27 & 0.93 & 0.89 & 0.78 & 0.00 & 0.54 & moderate \\
\hline 68 & 0.57 & 0.17 & 0.00 & 0.32 & 0.80 & 0.96 & 1.00 & 0.50 & 0.54 & moderate \\
\hline 69 & 0.57 & 0.17 & 0.00 & 0.32 & 0.96 & 0.96 & 0.73 & 0.50 & 0.54 & moderate \\
\hline 70 & 0.57 & 0.17 & 0.00 & 0.32 & 0.85 & 0.96 & 0.80 & 0.50 & 0.53 & moderate \\
\hline 71 & 0.57 & 0.17 & 0.67 & 0.32 & 0.85 & 0.86 & 0.73 & 0.00 & 0.52 & moderate \\
\hline 72 & 0.57 & 0.17 & 0.33 & 0.63 & 0.85 & 0.75 & 0.73 & 0.00 & 0.52 & moderate \\
\hline 73 & 0.57 & 0.17 & 0.00 & 0.32 & 0.91 & 0.86 & 0.73 & 0.50 & 0.52 & moderate \\
\hline 74 & 0.57 & 0.17 & 0.00 & 0.32 & 0.85 & 0.86 & 0.73 & 0.50 & 0.51 & moderate \\
\hline 75 & 0.57 & 0.17 & 0.33 & 0.00 & 0.91 & 0.86 & 0.73 & 0.50 & 0.50 & moderate \\
\hline 76 & 0.57 & 0.17 & 0.00 & 0.00 & 0.91 & 0.96 & 1.00 & 0.50 & 0.50 & moderate \\
\hline 77 & 0.43 & 0.25 & 0.00 & 0.40 & 0.80 & 0.80 & 0.67 & 0.50 & 0.49 & moderate \\
\hline 78 & 0.57 & 0.17 & 0.00 & 0.32 & 0.85 & 0.86 & 0.53 & 0.50 & 0.49 & moderate \\
\hline 79 & 0.57 & 0.17 & 0.33 & 0.32 & 0.85 & 0.86 & 0.80 & 0.00 & 0.49 & moderate \\
\hline 80 & 0.57 & 0.17 & 0.33 & 0.32 & 0.85 & 0.86 & 0.73 & 0.00 & 0.48 & low \\
\hline 81 & 0.57 & 0.17 & 0.33 & 0.63 & 0.85 & 0.75 & 0.33 & 0.00 & 0.48 & low \\
\hline 82 & 0.57 & 0.17 & 0.00 & 0.32 & 0.80 & 0.75 & 0.60 & 0.50 & 0.48 & low \\
\hline 83 & 0.43 & 0.25 & 0.00 & 0.00 & 0.80 & 0.94 & 1.00 & 0.50 & 0.47 & low \\
\hline 84 & 0.57 & 0.17 & 0.33 & 0.32 & 0.85 & 0.75 & 0.73 & 0.00 & 0.47 & low \\
\hline 85 & 0.57 & 0.37 & 0.67 & 0.00 & 0.85 & 0.86 & 0.53 & 0.00 & 0.46 & low \\
\hline 86 & 0.43 & 0.25 & 0.00 & 0.00 & 0.80 & 0.94 & 0.67 & 0.50 & 0.44 & low \\
\hline 87 & 0.43 & 0.25 & 0.00 & 0.00 & 0.80 & 0.94 & 0.67 & 0.50 & 0.44 & low \\
\hline 88 & 0.57 & 0.17 & 0.33 & 0.00 & 0.85 & 0.96 & 0.73 & 0.00 & 0.44 & low \\
\hline 89 & 0.57 & 0.37 & 0.67 & 0.00 & 0.80 & 0.75 & 0.33 & 0.00 & 0.42 & low \\
\hline 90 & 0.57 & 0.17 & 0.00 & 0.32 & 0.85 & 0.86 & 0.53 & 0.00 & 0.42 & low \\
\hline 91 & 0.43 & 0.25 & 0.00 & 0.00 & 0.80 & 0.80 & 0.41 & 0.50 & 0.40 & low \\
\hline 92 & 0.43 & 0.25 & 0.00 & 0.00 & 0.80 & 0.67 & 0.75 & 0.00 & 0.35 & low \\
\hline 93 & 0.43 & 0.25 & 0.00 & 0.00 & 0.80 & 0.80 & 0.41 & 0.00 & 0.33 & low \\
\hline 94 & 0.43 & 0.25 & 0.00 & 0.00 & 0.80 & 0.94 & 0.17 & 0.00 & 0.32 & low \\
\hline 95 & 0.14 & 0.00 & 0.00 & 0.00 & 0.53 & 0.53 & 0.50 & 0.00 & 0.21 & low \\
\hline
\end{tabular}

Note: the abbreviations of the indicators are as follows: FS: family size, DR: dependency ratio, IR: illiteracy ratio $(15+)$, RPW: ratio of perennial work in other places, PCI: income per capita, AHI: access to hazard-related information, VPC: vehicles per capita and HRT: hazard-related training. 
Appendix B: Procedures and results using principle component analysis (PCA) to determine the weights of indicators

There are four steps to calculate the weights of indicators using PCA with the help of SPSS software.

The first step is using the KMO test (Kaiser-MeyerOlkin). A KMO value higher than 0.5 demonstrates that the sampling data are suitable to perform PCA (Lolli and Di Girolamo, 2015). The KMO value, calculated for indicator variables in Appendix A: The standard data and assessment results is 0.757 , which indicates that it is suitable to perform PCA.

The second step is to calculate initial eigenvalues and rotated eigenvalues of the PCA, including total initial eigenvalue, variance $(\%)$ and cumulative $(\%)$. The value of cumulative (\%) should be equal or higher than $80 \%$, which demonstrates that the information of the extracted principle components could cover most of the information of the initial indictors. Table B1 shows the initial eigenvalues and rotated eigenvalues of the PCA performed on the indicator variables in Appendix A.

The third step is to calculate the values of the rotated component matrix (Table B2).

The fourth step is to calculate the weights of each indicator. The weight of the $i$ th indicator $\left(w_{i}\right)$ can be expressed by

$$
w_{i}=\frac{\sum_{j=1}^{k}\left(\frac{a_{i j}}{\sqrt{\lambda_{j}}} \times v_{j}\right)}{\sum_{i=1}^{n}\left[\sum_{j=1}^{k}\left(\frac{a_{i j}}{\sqrt{\lambda_{j}}} \times v_{j}\right)\right]} i=1,2 \ldots 8, j=1,2,3,4,
$$

where $a_{i j}$ is the value of the $i$ th indicator at the $j$ th rotated principle component and $\lambda_{j}$ and $v_{j}$ are the values of total initial eigenvalue and variance (\%) at the $j$ th rotated principle component, respectively.

The weights of all indicators can then be obtained using Eq. (B1) as follows: $w=\left[w_{1}, w_{2}, \ldots w_{8}\right]=$ $[0.14,0.12,0.12,0.12,0.16,0.16,0.08,0.11]$.

In order to make the results more suitable for the local situation, 20 experts from different fields (geography, hydrology, sociology and risk management) were invited to evaluate and adjust the weights. Finally, the weights listed in Table 1 were used in this paper. 
Table B1. Initial eigenvalues and rotated eigenvalues of PCA performed on the indicator variables in Appendix A.

\begin{tabular}{|c|c|c|c|c|c|c|}
\hline \multirow[t]{2}{*}{ Component } & \multicolumn{3}{|c|}{ Initial eigenvalues } & \multicolumn{3}{|c|}{ Rotated eigenvalues } \\
\hline & Total & Variance $(\%)$ & Cumulative (\%) & Total & Variance $(\%)$ & Cumulative (\%) \\
\hline 1 & 3.33 & 41.6 & 41.6 & 2.39 & 29.8 & 29.8 \\
\hline 2 & 1.28 & 16.0 & 57.5 & 1.49 & 18.6 & 48.4 \\
\hline 3 & 1.02 & 12.8 & 70.3 & 1.41 & 17.7 & 66.1 \\
\hline 4 & 0.77 & 9.7 & 80.0 & 1.11 & 13.9 & 80.0 \\
\hline 5 & 0.62 & 7.8 & 87.8 & & & \\
\hline 6 & 0.42 & 5.3 & 93.1 & & & \\
\hline 7 & 0.32 & 4.0 & 97.1 & & & \\
\hline 8 & 0.23 & 2.9 & 100.0 & & & \\
\hline
\end{tabular}

Table B2. Rotated component matrix.

\begin{tabular}{lrrrr}
\hline & \multicolumn{4}{c}{ Component } \\
\cline { 2 - 5 } & 1 & 2 & 3 & 4 \\
\hline FS & 0.87 & 0.22 & 0.01 & 0.09 \\
DR & 0.17 & 0.05 & 0.08 & 0.93 \\
IR & 0.07 & 0.88 & 0.09 & 0.12 \\
RPW & 0.37 & 0.76 & 0.00 & -0.07 \\
PCI & 0.86 & 0.22 & 0.18 & 0.11 \\
AHI & 0.65 & 0.15 & 0.51 & 0.13 \\
VPC & 0.52 & -0.03 & 0.53 & -0.42 \\
HRT & 0.09 & 0.06 & 0.91 & 0.09 \\
\hline
\end{tabular}

Extraction method: principle component analysis. Rotation method: varimax with Kaiser normalization. 
Acknowledgements. This study was supported by the National Natural Science Foundation of China (grant no. U1504705), Humanities \& Social Science Research Project of the Education Department, Henan province (grant no. 2014-gh-060), and the Fundamental Research Funds for the Universities of Henan province (grant no. NSFRF140149). The authors also express thanks for the insightful and constructive comments from the reviewers and the editor.

Edited by: T. Glade

Reviewed by: two anonymous referees

\section{References}

Bjarnadottir, S., Li, Y., and Stewart, M. G.: Social vulnerability index for coastal communities at risk to hurricane hazard and a changing climate, Nat. Hazards, 59, 1055-1075, 2011.

Chambers, R.: Participatory rural appraisal (PRA): analysis of experience, World Develop., 22, 1253-1268, 1994.

Chen, W. F., Cutter, S. L., Emrich, C. T., and Shi, P. J.: Measuring Social Vulnerability to Natural Hazards in the Yangtze River Delta Region, China, Int. J. Disast. Risk Sc., 4, 169-181, 2013.

Cornwall, A. and Pratt, G.: The use and abuse of participatory rural appraisal: reflections from practice, Agr. Hum. Values, 28, 263272, 2011.

Cutter, S. L. and Finch, C.: Temporal and spatial changes in social vulnerability to natural hazards, P. Natl. Acad. Sci. USA., 105, 2301-2306, 2008.

Cutter, S. L., Boruff, B. J., and Shirley, W. L.: Social vulnerability to environmental hazards. Social science quarterly, 84, 242-261, 2003.

Cutter, S. L., Emrich, C. T., Morath, D. P., and Dunning, C. M.: Integrating social vulnerability into federal flood risk management planning, J. Flood Risk Manag., 6, 332-344, 2013.

Eakin, H. and Bojorquez-Tapia, L. A.: Insights into the composition of household vulnerability from multicriteria decision analysis, Global Environ. Change, 18, 112-127, 2008.

Garbutt, K., Ellul, C., and Fujiyama, T.: Mapping social vulnerability to flood hazard in Norfolk, England, Environ. Hazards-Uk, 14, 156-186, 2015.

Ghimire, Y. N., Shivakoti, G. P., and Perret, S. R.: Household-level vulnerability to drought in hill agriculture of Nepal: implications for adaptation planning, Int. J. Sust. Dev. World, 17, 225-230, 2010.

Harrell, M. C. and Bradley, M. A.: Data collection methods, Semistructured interviews and focus groups, Rand National Ddfense Research Inst., Santa Monica, CA, 2009.

Hsieh, C. H.: Disaster risk assessment of ports based on the perspective of vulnerability, Nat. Hazards, 74, 851-864, 2014.

Li, H., Zhang, P., and Cheng, Y.: Concepts and assessment methods of vulnerability, Prog. Geogr., 27, 18-25, 2008.

Linnekamp, F., Koedam, A., and Baud, I. S. A.: Household vulnerability to climate change: Examining perceptions of households of flood risks in Georgetown and Paramaribo, Habitat Int., 35, 447-456, 2011.

Liu, D. L. and Liang, H. Q.: Social vulnerability assessment for regional natural disasters-A case study of He'nan province, Bull. Soil Water Conserv., 34, 128-134, 2014.
Liu, D. L., Hao, S. L., Liu, X. Z., Li, B. C., He, S. F., and Warrington, D. N.: Effects of land use classification on landscape metrics based on remote sensing and GIS, Environ. Earth. Sci., 68, 22292237, 2013.

Lolli, S. and Di Girolamo, P.: Principal component analysis approach to evaluate instrument performances in developing a costeffective reliable instrument network for atmospheric measurements, J. Atmos. Ocean. Tech., 32, 1642-1649, 2015.

Murphy, E. and Scott, M.: Household vulnerability in rural areas: Results of an index applied during a housing crash, economic crisis and under austerity conditions, Geoforum, 51, 75-86, 2014.

Noriega, G. R. and Ludwig, L. G.: Social vulnerability assessment for mitigation of local earthquake risk in Los Angeles County, Nat. Hazards, 64, 1341-1355, 2012.

$\mathrm{Qu}, \mathrm{Q}$.: Determination of weights for the ultimate cross efficiency: A use of principal component analysis technique, J. Softw., 7, 2177-2181, 2012.

Shao, L. F., Peng, Z. W., Wang, S. N., Dai, W., Hu, Y. Y., and Yu, H. M.: Classification of "7 · 24" Rainstorm Deris Flow on Start-up Model in Luanchuan County of Henan, China, J. Mt. Sci., 31, 334-341, 2013.

Siagian, T. H., Purhadi, P., Suhartono, S., and Ritonga, H.: Social vulnerability to natural hazards in Indonesia: driving factors and policy implications, Nat. Hazards, 70, 1603-1617, 2014.

Terry, C. and Lisa, S.: World disasters report 2014: Focus on culture and risk, International Federation of Red Cross and Red Crescent Societies, 2014.

Walter, J.: World disasters report 2004: Focus on community resilience, Kumarian, 2004.

Wang, W. D., Guo, J., Fang, L. G., and Chang, X. S.: A subjective and objective integrated weighting method for landslides susceptibility mapping based on GIS, Environ. Earth Sci., 65, 17051714, 2012.

Werg, J., Grothmann, T., and Schmidt, P.: Assessing social capacity and vulnerability of private households to natural hazards - integrating psychological and governance factors, Nat. Hazards Earth Syst. Sci., 13, 1613-1628, doi:10.5194/nhess-131613-2013, 2013.

Xi, X. H.: Empirical Research on the Dynamic Development of the Relative Poverty of Rural Residents in Henan Province, J. Anhui Agri. Sci., 40, 9933-9935, 2012.

Zebardast, E.: Constructing a social vulnerability index to earthquake hazards using a hybrid factor analysis and analytic network process (F'ANP) model. Nat. Hazards, 65, 1331-1359, 2013.

Zhang, B., Yuan, H. Y., Huang, Q. Y., Wen, R. Q., and Gu, J. Q.: Research on fine spatial quantitative model about vulnerability of hazard-affected bodies, Int. J. Digit. Earth, 3, 395-405, 2010.

Zhang, Y. L. and You, W. J.: Social vulnerability to floods: a case study of Huaihe River Basin, Nat. Hazards, 71, 2113-2125, 2014.

Zhou, Y., Li, N., Wu, W. X., and Wu, J. D.: Assessment of provincial social vulnerability to natural disasters in China, Nat. Hazards, 71, 2165-2186, 2014. 